\title{
ADRENAL DISORDERS I: CUSHING'S SYNDROME AND ITS PUZZLES*
}

BY

\author{
LAWSON WILKINS \\ From the Department of Paediatrics, Johns Hopkins School of Medicine, Baltimore
}

(RECEIVED FOR PUBLICATION JULY 19, 1961)

Birmingham has become my favourite spot on this side of the Atlantic because of the warm hospitality which my friends here have always shown. On our side of the ocean and throughout the world your city is famous because of the advances made here in knowledge concerning the diseases of infancy and childhood. These were due both to personal contributions of that great leader of paediatrics, Sir Leonard Parsons, and to the work of disciples whom he trained and inspired. There is no need for me to review here his many achievements. I can only marvel at his great energy and his versatility and breadth of interest in many fields. I wish I could have known him personally, because I can sense his real humanity, kindliness, gentleness and charm.

I consider the privilege of giving lectures in memory of Sir Leonard Parsons one of the greatest honours in my life and I can only feel most humble in doing so.

\section{The Diversity of Adrenal Disorders}

The tiny adrenal glands, first described by Eustachius in 1563 , were so modestly hidden away deep in the flanks behind the kidneys, that for almost four centuries they remained unknown to most laymen until about 15 years ago, when their indispensability both in health and disease was loudly broadcast by the popular press in the new terminologies of stresses and adaptation. We doctors, however, have had a speaking acquaintance with the diseases of the adrenals for a little over a century.

I trust that my ancient age will give me the privilege of looking backward over my shoulder to glimpse the steps by which our present knowledge was attained.

In 1855 Thomas Addison of Guy's Hospital, being particularly interested in dermatology, was attracted by the peculiar brown pigmentation of the skin and mucous membranes, which occurred in certain patients who became exceedingly weak,

\footnotetext{
* The Leonard Parsons Memorial Lectures, 1961
}

asthenic and hypotensive and lost weight progressively without apparent reason. With relatively slight infections they would go abruptly into circulatory collapse and die. At autopsy he found the adrenal glands destroyed, usually by tuberculosis. It was not, however, until 1933 that Robert Loeb and George Harrop, working at Hopkins, proved that the circulatory collapse of Addison's disease was due to loss of large amounts of sodium and water and that the administration of salt was an essential part of treatment (Loeb, Atchley, Benedict and Leland, 1933; Harrop, Weinstein, Soffer and Trescher, 1933). A blond-headed boy named George Thorn came down from Buffalo to join the group and acquired a pack of purely-bred basset hounds to study in detail the effects of adrenalectomy and treatment with salt and some of the new extracts of the adrenal cortex being prepared by Hartman, Swingle and Pfiffner and others (Hartman, Aaron and Culp, 1930; Pfiffner and Swingle, 1929).

About 50 years ago it became recognized that some women with adrenal tumours became masculinized and bearded, and also that external genitalia resembling the male were found in female infants born with very large adrenal glands. These female pseudohermaphrodites either died during the first few weeks of life with unexplained dehydration and collapse, or, if they remained healthy, they grew exceedingly rapidly, were very strong and muscular, and became progressively more masculinized and hirsute, developing no feminine characteristics.

In 1932 I attended the meeting of the Johns Hopkins Medical Society at which the surgeon, Harvey Cushing, came back to his alma mater and described a new disorder (Cushing, 1932). These patients became weak and easily fatigued; their muscles and other protein tissues wasted; there were haemorrhages and striae in the skin; fat accumulated in a peculiar distribution so that the face became moon-like, blood pressure was elevated, the skin was plethoric, and the blood sugar was high. If the disease began in childhood, growth 


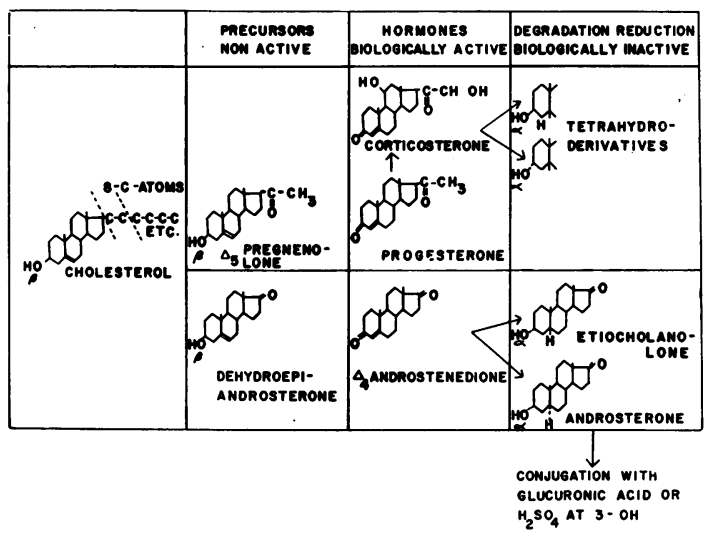

Fig. 1.-Synthesis and degradation of steroidal hormones.

and osseous development were retarded rather than accelerated as they were in the adrenogenital syndrome. Cushing thought this disease was due primarily to a basophil adenoma of the pituitary, although some patients had adrenal tumours. After the actions of various adrenal hormones became known, Haymaker and Anderson (1938) and Albright (1943) pointed out very clearly that all of the symptoms and metabolic abnormalities of Cushing's syndrome could be explained by the overproduction of the adrenal hormones. Today many workers are beginning to believe that Cushing may have been right after all.

As recently as 1955 Jerome Conn described an entirely different disorder in which a tumour of the adrenal cortex caused high blood pressure and episodes of muscular paralysis or tetanic spasms associated with very low serum potassium (Conn, 1955).

How could these four diseases of the adrenal cortex with such markedly different symptoms be explained, particularly when three of them were associated with neoplasms or hyperactivity of the gland? (I have purposely omitted phaeochromocytomas which arise from the adrenal medulla.) To answer this question required the patient work of many students, physiologists, chemists and clinical investigators. Chemists had to devise new methods for isolating pure steroids from the adrenals and for measuring minute amounts present in the blood or excreted in the urine as altered degradation products. Their exact molecular structures had to be determined. These compounds and others with slightly altered structures had to be synthesized and their biological effects studied in animals. To determine which compounds were actually secreted as hormones by the adrenals and which were artefacts or degradation products, perfusion experiments had to be carried out on isolated adrenal glands. The precursors of these steroids and their pathways of biosynthesis had to be determined. The patterns of steroid secretion or abnormalities of biosynthesis had to be studied in each of the clinical syndromes mentioned. In recent years the enzymologists and geneticists have made their contributions particularly in studying the adrenogenital syndrome. I would like to emphasize that the study of these clinical syndromes, which are 'experiments of Nature' not reproducible in the laboratory, contributes much to the understanding of the normal biosynthesis and physiology of adrenocortical hormones.

\section{Types of Adrenal Steroids and their Actions}

It will be necessary now to point out briefly some of the high spots of steroid chemistry. As shown in Fig. 1, the adrenal steroids are derived from cholesterol by the cission of either six or eight of the carbon atoms in the chain attached at $\mathrm{C}_{17}$. This results in the formation of $\Delta 5$-pregnenolone, a 21-carbon steroid, or dehydroepiandrosterone, a 19-carbon steroid. Both of these are biologically inactive precursors of adrenal hormones and like cholesterol they have a double bond at $\mathrm{C}_{5 \cdot 6}$ and a hydroxyl at $\mathrm{C}_{3}$ in the beta position. For the formation of biologically active steroids such as progesterone and $\Delta_{4}$ androstenedione the double bond must be shifted to $\mathrm{C}_{4-5}$ and the hydroxyl at $\mathrm{C}_{3}$ converted to ketone. The degradation of these hormones to inactive metabolites by the liver consists of reduction of the A ring with removal of the double bond and the conversion of the $C_{3}$ ketone to a 3-alpha-hydroxyl. These compounds, known as tetrahydro-derivatives are made water soluble by conjugation of the $\mathrm{C}_{3}$ hydroxyl with glucuronic or sulphuric acids so that they can be readily excreted in the urine.

Although 40 or more $21-\mathrm{C}$ and $19-\mathrm{C}$ steroids have been isolated from adrenal tissue or from the urine, very few of these are actually synthesized in the adrenal cortex and secreted into the adrenal veins. The true products of the adrenals have been measured in perfusion or tissue slice experiments after giving tagged precursors and stimulating the adrenal glands with A.C.T.H. or by cannulating the human adrenal gland. As shown in Fig. 2, the principal steroid of the human adrenal is hydrocortisone (17-hydroxycorticosterone or Compound F) secreted at the rate of 9-15 mg. per day. A closely related compound, corticosterone (Compound $B$ ), is found in about one-quarter of the amount of Compound $F$ in the human being, but these ratios vary in different species. Both these compounds 
have gluconeogenetic actions, but Compound B has slight Na-retaining properties and does not have the anti-inflammatory activity of Compound F. The exceedingly potent Na-retaining steroid, aldosterone, was not isolated or identified until 1955, because it is present in such small amounts, i.e. only $200 \mu \mathrm{g}$. per day. The so-called adrenal androgens are 19-carbon steroids, related to testosterone. $\Delta_{4}$ androstenedione and adrenosterone are representatives, although we are not sure of the exact structure and amounts of the compounds formed by the normal adrenal. The dotted lines show the chemical structures measured as the metabolites 17-hydroxycorticoids and 17-ketosteroids.

Our knowledge concerning the physiological actions of the gluconeogenetic hormones dates back to studies made by Long, Katzin and Fry (1940), using crude but active extracts of the adrenals before purified steroids had been isolated. They promote the deamination of amino acids and their conversion into carbohydrate, thus preventing the depletion of liver glycogen which occurs on fasting. They also decrease the utilization of glucose by muscle, thus opposing the action of insulin. They inhibit protein anabolism (or may be actually catabolic) and in excess inhibit growth and osseous development. They affect the utilization of fat and its distribution in the body, leading to a characteristic type of obesity in Cushing's syndrome. After cortisone became available its pharmacodynamic or anti-inflammatory effects, when given in greater than physiological amounts, became apparent (Ingle and Baker, 1953). These were destruction of lymphocytes and eosinophils and inhibition of inflammatory or connective tissue reaction causing increased susceptibility to infections and gastric ulcer. On the other hand they suppress the injury that results from the reaction of the antigen and antibody combination upon the body cells in hypersensitivity states. Aldosterone exerts its effects entirely on $\mathrm{Na}$ and $\mathrm{K}$ regulation both in renal, sweat and salivary excretion and on intracellular distribution (Gaunt, 1955). The mechanism through which aldosterone may cause hypertension is not clearly understood. Androgens are protein-anabolic and growth-promoting in direct contrast to the antianabolic effects of the glucocorticoids (Dorfman and Shipley, 1956). In normal females they are probably responsible for the protein-anabolic growth spurt which occurs at puberty and for the appearance of sexual hair and seborrhoea.

Let us now consider what abnormalities of adrenal function are responsible for some of the clinical disorders which we have mentioned previously. We shall confine ourselves now to Cushing's syndrome,

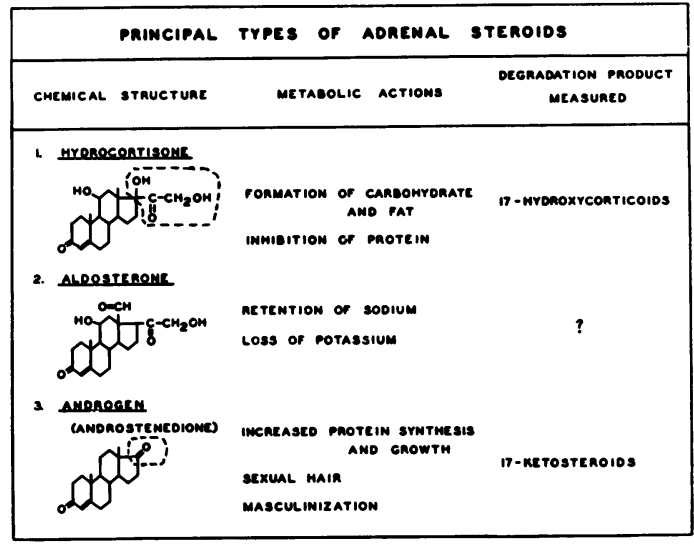

FIG. 2.-Principal types of adrenal steroids.

The dotted lines encircle the chemical structures measured as 17 hydroxycorticosteroids and 17-ketosteroids.

and in a later paper to the adrenogenital syndrome.

\section{Cushing's Syndrome}

It has been generally accepted that all the clinical manifestations of Cushing's syndrome are due to hypersecretion of the adrenocortical hormones. As shown in Table 1, most of these are due to the inhibition of protein anabolism by excessive gluconeogenetic steroids (cortisol and Compound B). However, increased salt retaining hormone, aldosterone, and adrenal androgens are responsible in varying degrees for some of the symptoms. The entire clinical picture of Cushing's syndrome can be produced by the prolonged administration of A.C.T.H., or for that matter of cortisol. When it became possible to measure in the blood and in the urine cortisol and its metabolites as 17-hydroxycorticoids, it was demonstrated that these were

TABLE 1

POSSIBLE CAUSE OF SYMPTOMS IN CUSHING'S SYNDROME

\begin{tabular}{|c|c|c|}
\hline $\begin{array}{l}\text { Increased } \\
\text { Glycogenetic } \\
\text { Hormone }\end{array}$ & $\begin{array}{l}\text { Increased } \\
\text { Electrolyte- } \\
\text { controlling } \\
\text { Hormone }\end{array}$ & $\begin{array}{l}\text { Increased } \\
\text { Androgen }\end{array}$ \\
\hline $\begin{array}{l}\text { Diminished N-anabolism } \\
\text { Retarded growth }\end{array}$ & \multirow{4}{*}{$\begin{array}{l}\text { Hypertension } \\
\text { Increased blood } \\
\text { volume } \\
\text { Serum Na increased } \\
\text { Serum K decreased }\end{array}$} & \multirow{4}{*}{$\begin{array}{l}\text { Hirsutism } \\
\text { Acne } \\
\text { Decreased ovarian } \\
\text { function } \\
\text { Increased output of } \\
\text { 17-ketosteroids }\end{array}$} \\
\hline $\begin{array}{l}\text { Muscular weakness } \\
\text { Friability of capillaries } \\
\text { and skin } \\
\text { Osteoporosis }\end{array}$ & & \\
\hline $\begin{array}{l}\text { Diabetic sugar curve } \\
\text { Insulin resistance } \\
\text { Tendency to obesity }\end{array}$ & & \\
\hline $\begin{array}{l}\text { Increased output of } \\
\text { 'corticoids' }\end{array}$ & & \\
\hline
\end{tabular}




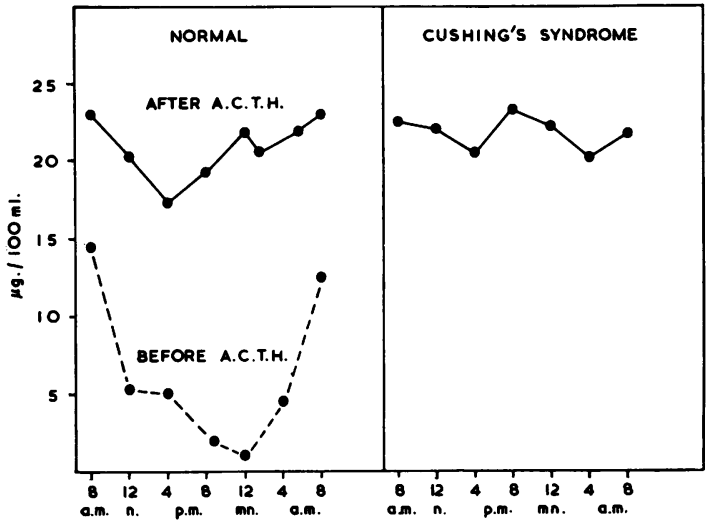

FIG. 3.-Diurnal variations in plasma-17-OH-CS. (Nugent et al., 1960.)

On the left is shown the diurnal variation in plasma 17-OH-CS in normal individuals and its disappearance after constant infusion of 4-5 i.u. A.C.T.H. daily for four days. On the right is shown the absence of diurnal variations in patients with Cushing's syndrome.

invariably increased in Cushing's syndrome. Furthermore, no abnormal steroids were found in the blood or urine nor was there any disproportion in the ratio of the different types of normal adrenal steroids. Accordingly, there is no evidence of any abnormality of either the synthesis or degradation of the adrenal hormones such as occurs in the

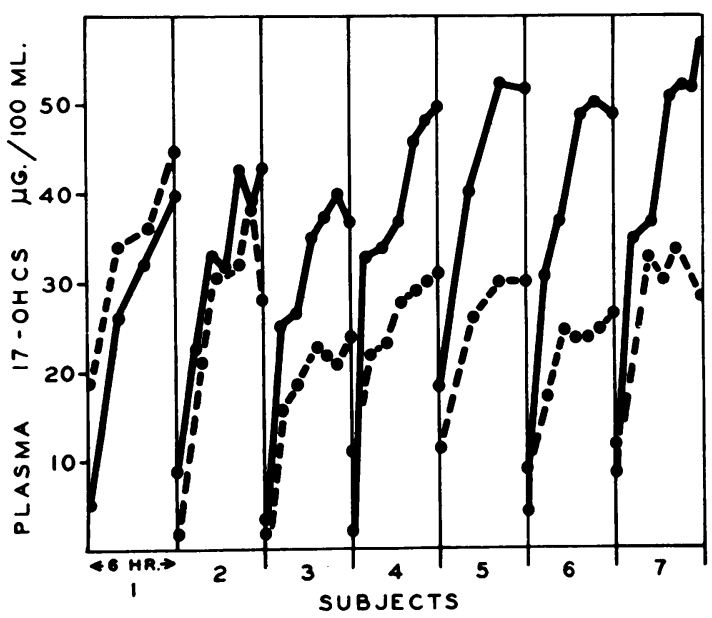

FIG. 4.-Effect of four-day A.C.T.H. infusions on adrenal responsiveness. (Nugent et al., 1960.)

Broken lines show rises of plasma corticoids resulting from $25 \mathrm{i} . \mathrm{u}$ A.C.T.H. given intravenously over six hours in seven normal subjects. Solid lines show same A.C.T.H. tests performed after the subjects had received constant infusions of 4-5 i.u. A.C.T.H. daily for four days. Five subjects showed increased responsiveness similar to that seen in Cushing's syndrome. adrenogenital syndrome. This all points to merely a 'simple' overproduction of adrenal hormones.

But this is not so simple as it sounds when one begins to investigate the matter further. When Cushing's syndrome is associated with an adrenal adenoma and is cured by its surgical removal, there can be no doubt that the overproduction of the hormones is due to the neoplasm. But what about those cases in which there is a diffuse hyperplasia of the adrenals or the occasional case in which the adrenals are scarcely enlarged at all? Is the overproduction of steroids due primarily to an autonomous overactivity of the adrenal cells or is it caused by excessive stimulation by pituitary A.C.T.H.? One might be inclined to jump to the second conclusion since the adrenocortical secretion of cortisol is normally governed by the amount of A.C.T.H. secreted. However, a number of objections must be overcome before accepting this hypothesis: 1 . It has not been possible to measure increased A.C.T.H. in the blood of patients with Cushing's syndrome, although it is greatly increased in the adrenogenital syndrome and in Addison's disease. 2. Why does the increased blood cortisol operating through the homeostatic regulatory mechanism of the hypothalamic-pituitary-adrenal axis, not inhibit further secretion of A.C.T.H. and bring the levels of cortisol back to normal? 3. Why are the adrenals in Cushing's syndrome more sensitive than normal to stimulation by exogenous A.C.T.H. when one might expect that high levels of endogenous A.C.T.H. would cause decreased responsiveness to the exogenous test?

During the past year a number of workers have provided at least partial answers to these objections.

Nugent, Eik-Nes, Kent, Samuels and Tyler (1960), at Salt Lake City, postulated that Cushing's syndrome might be caused by a constant, but only slightly increased, secretion of A.C.T.H. in concentrations which could not be detected in the plasma by the present bio-assay methods. Accordingly, they gave to healthy volunteers intravenous infusions of A.C.T.H. over four-day periods at constant rates which were so small that they would not lead to detectable concentrations in the blood. In four young men, who received 4 to 5 i.u. per day for four days, there were constant elevations of plasma 17-hydroxycorticoids and the normal diurnal variations disappeared. As shown in Fig. 3, these patterns were quite similar to those seen in patients with Cushing's syndrome. Likewise, as seen in Fig. 4, in five of seven normals the four-day infusion of A.C.T.H. caused increased responsiveness to maximal stimulation with A.C.T.H. (giving 25 i.u. intravenously over a six-hour period) similar to that 
which is seen in patients with Cushing's syndrome. These workers concluded that the possibility that Cushing's syndrome associated with adrenal hyperplasia might result from increased secretion of A.C.T.H. could not be excluded on the grounds that increased blood levels could not be demonstrated; and they believed the disorder might result from a fairly constant secretion of a small amount of A.C.T.H. by the pituitary gland, i.e. pituitary 'dribbling' of A.C.T.H. The findings, however, do not indicate whether the site of the abnormality responsible for this secretion is in the hypothalamus, the pituitary, the interconnecting pathways or in some other controlling mechanism.

Grant Liddle, of Vanderbilt, investigated the problem further by studying the relative resistance of A.C.T.H. secretion to suppression by corticoids (Liddle, 1960). Other workers had had inconsistent results with suppression tests when using 9-alphafluorocortisol, but Liddle used the exceedingly potent steroids $\Delta^{1}$-9-alpha-fluorocortisol $\left(\Delta_{1} \mathrm{FF}\right)$ and dexamethasone. When these are given in doses of $0.5 \mathrm{mg}$. every six hours to normal adults or patients who do not have Cushing's syndrome, the urinary 17-hydroxycorticoids are invariably reduced to less than $2.5 \mathrm{mg}$. and sometimes to 0 on the second day of the test (Fig. 5). All 27 patients with Cushing's syndrome, not due to adrenal tumour, showed definite resistance to suppression when these steroids were given in doses of $0.5 \mathrm{mg}$. In no case did the 17-hydroxycorticoids fall to less than $4 \mathrm{mg}$., and in 16 cases there was practically no change in the excretion. However, when these patients were retested with doses of $2 \mathrm{mg}$. every six hours the 17-hydroxycorticoids fell on the second or third day to less than $50 \%$ of the base value. It is apparent that although these patients have increased resistance to the suppressive effects of these steroids, their pituitary-adrenal systems are not absolutely autonomous, but can be suppressed when sufficiently large doses are employed. On the other hand, eight patients with Cushing's syndrome due to proved adrenal tumours resisted the suppressive influence of even large $(2 \mathrm{mg}$.) doses of $\Delta^{1} \mathrm{FF}$. Additional studies of Liddle are summarized in Table 2. Unilateral or subtotal adrenalectomy in the patients without tumour, caused no change in the resistance to A.C.T.H. suppression. Of 18 patients who were treated by irradiation of the pituitary, 10 were not improved clinically and continued to show resistance to suppression, while eight had clinical remissions. Six of these eight were tested for A.C.T.H. suppression and three of these showed normal suppressibility after irradiation of the pituitary. Four patients with Cushing's

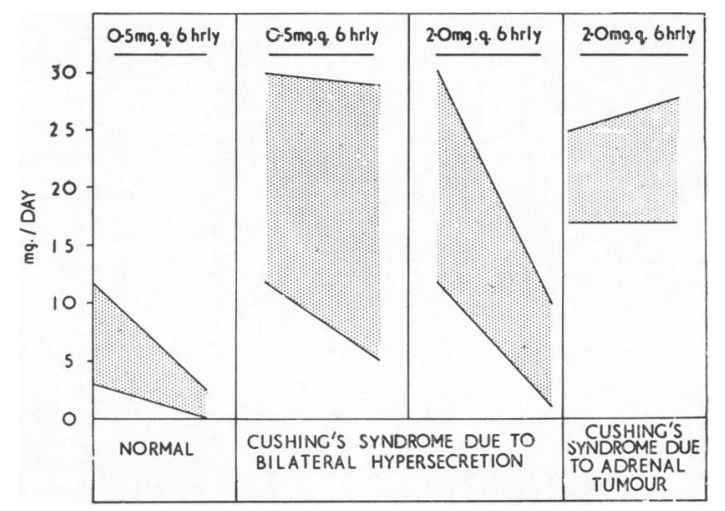

FIG. 5.-Suppression of urinary 17-OH-CS with $\Delta^{1}$ FF $\left(\Delta^{1}-9\right.$-alphafluorocortisol) (adapted from data of Liddle (1960)).

Shaded areas show upper and lower limits found in groups studied.

syndrome had enlarged sella turcicas suggesting the presence of a pituitary adenoma. In all of these four cases there was abnormal resistance to small doses of $\Delta^{1} \mathrm{FF}$, but definite suppression with the larger doses. This suggested that, whereas the pituitary adenoma was associated with a disturbance in A.C.T.H. homeostasis, the A.C.T.H.-secreting mechanism had not become autonomous, but was still influenced by the levels of circulating corticosteroids.

The test for suppression of A.C.T.H. distinguishes the cases of Cushing's syndrome which are dependent upon A.C.T.H. secretions from those due to autonomous adrenocortical hypersecretion such as occurs with adrenal neoplasms. The demonstration that there is partial impairment of the A.C.T.H.

TABLE 2 SUMMARY OF SUPPRESSION TESTS IN VARIOUS TYPES
OF CUSHING'S SYNDROME (Liddle, 1960)

\begin{tabular}{|c|c|c|}
\hline \multirow{2}{*}{ Type of Disorder } & \multicolumn{2}{|c|}{$\begin{array}{l}\text { Suppression of 17-hydroxy- } \\
\text { corticoids by } \Delta^{1} \text { FF }\end{array}$} \\
\hline & $\begin{array}{l}0.5 \mathrm{mg} . \\
6 \text { hourly }\end{array}$ & $\begin{array}{l}2 \cdot 0 \mathrm{mg} . \\
6 \text { hourly }\end{array}$ \\
\hline 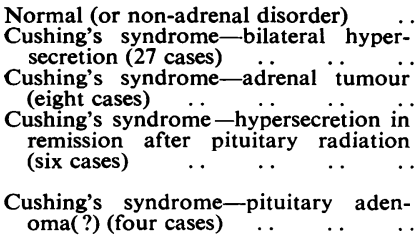 & $\begin{array}{c}+ \\
0 \\
0 \\
(3 \text { of } 6) \\
0\end{array}$ & $\begin{array}{l}+ \\
+ \\
0\end{array}$ \\
\hline
\end{tabular}

+ indicates suppression of 17-hydroxycorticoid by administration of $\Delta^{\mathbf{1}} \mathrm{FF}$.

0 indicates failure of suppression of 17-hydroxy corticoids by $\Delta^{1} \mathrm{FF}$. 

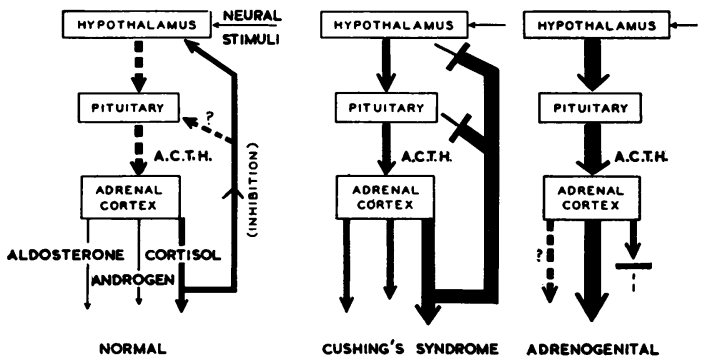

FIG. 6.-The hypothalamic-pituitary-adrenal axis and the probable defects in Cushing's syndrome and the adrenogenital syndrome. Adrenal activity is regulated by the plasma level of cortisol through the A.C.T.H. secreting mechanism of the hypothalamus and pituitary. Normally when the cortisol concentration rises above physiological requirements A.C.T.H. secretion is inhibited. This intermittent inhibition may account for the normal diurnal fluctuations.

In Cushing's syndrome high levels of cortisol do not suppress the A.C.T.H. secretion as they normally do. Accordingly there is a constant, though not greatly elevated, secretion of A.C.T.H. and diurnal variations do not occur.

In the adrenogenital syndrome there is a defect in the synthesis of cortisol and secretion of androgenic precursors. To compensate for this there is greatly increased secretion of A.C.T.H.

suppressive effects of the adrenocortical steroids explains why hypersecretion continues to be maintained in spite of the supraphysiological concentration of plasma cortisol. Therefore, the primary disorder must be an abnormality of the homeostatic regulatory mechanism of the hypothalamic-pituitaryadrenal axis (Fig. 6). The findings of Nugent et al. (1960), which we have quoted previously, also suggest that the disorder is not due to a grossly excessive secretion of A.C.T.H., but rather to the inability of rising concentrations of plasma cortisol to turn off the production of A.C.T.H. and allow a fall in the adrenal output to occur. This accounts also for absence of the normal diurnal variation in corticoid levels which is a characteristic feature of Cushing's syndrome.

The precise location of this homeostatic regulatory centre of adrenal activity is not definitely known. Is the pituitary itself directly responsive to adrenocortical steroids, or is the pituitary activity in turn governed by a corticotropin-releasing neurohormone of the hypothalamus? Is it possible that the primary disorder in Cushing's syndrome with bilateral adrenal hypersecretion could be the abnormal secretion of this neurohormone, and is it possible that its excess might occasionally even cause the formation of an A.C.T.H.-secreting adenoma of the pituitary?

This brings us finally to the problem of the rational treatment of Cushing's syndrome, when it is not due to adrenal tumours, and to a consideration of the pituitary tumours which have been reported to develop after adrenalectomy.
External irradiation of the pituitary has caused prolonged remissions and occasional 'cures' in some cases of Cushing's syndrome not associated with adrenal tumours nor accompanied by evidences of a pituitary adenoma. Liddle states that about $40 \%$ of patients treated by pituitary irradiation responded with a decrease in basal corticosteroid excretion to normal levels. Some of the successfully treated patients returned to normal adrenal responsiveness to A.C.T.H. and normal A.C.T.H. suppression by corticoids. In others, however, there was still abnormal resistance to suppression in spite of clinical improvement. Subtotal adrenalectomy has been relatively disappointing, as after varying intervals relapses frequently occur. Tests for A.C.T.H. responsiveness and A.C.T.H. suppression do not indicate that the fundamental disorder has been corrected. Total adrenalectomy followed by substitution therapy with adrenal hormones at physiological levels became popular and for a while seemed to be a rational solution. In the past few years, however, there has been an increasing number of reports (Salassa, Kearns, Kernohan, Sprague and MacCarty, 1959; Nelson, Meakin and Thorn, 1960) of expanding pituitary tumours accompanied by the 'hyperpigmentation syndrome' following either total or subtotal adrenalectomy. An interesting case of ours is illustrative.

Case Report. P.S. had developed progressive obesity with a moon-face between the ages of 6 and 10 years. When we first saw her in 1951 at the age of 10 years she was stunted in growth with a height age of $8 \frac{1}{2}$ years and a bone age of $9 \frac{1}{2}$ years. Her face was round and plethoric with considerable acne. There were reddish striae on the trunk. Pubic hair was increased; breasts and vagina were undeveloped. There was no hypertension. The glucose tolerance curve was suggestively diabetic. Urinary 17-ketosteroids were 14-17 mg. per day, the '11-oxysteroids' were $1.7 \mathrm{mg}$. per day (normal $<0.8 \mathrm{mg}$.). At this time there was no unusual pigmentation of the skin. Radiographs showed a small sella turcica. Exploration of the adrenals revealed no tumour, but there was moderate bilateral hyperplasia. Her subsequent course is summarized in Table 3.

In January 1952, she was treated by irradiation of the pituitary receiving a total of only 2,600 roentgen units. This caused temporarily very little, if any, clinical improvement, although she grew one and a half inches and had one menstrual period. However, during 1953 and 1954 there was progressive worsening until by April 1954 she presented a more marked picture of Cushing's syndrome than ever and had florid red striae and ecchymoses. There was no abnormal pigmentation. At this time the 17-ketosteroids were 6-12 mg./day, and the urinary 17-hydroxycorticoids $12 \mathrm{mg}$./day. There was a sensitive response to A.C.T.H., the plasma 17-hydroxycorticoids rising from 15 to $55 \mu \mathrm{g}$. on an intravenous 
TABLE 3

SUMMARY OF CASE OF HYPERPIGMENTATION DEVELOPING AFTER ADRENALECTOMY FOR CUSHING'S SYNDROME

\begin{tabular}{|c|c|c|c|c|c|c|c|}
\hline Date & & $\begin{array}{l}\text { Cushing's } \\
\text { Signs }\end{array}$ & Melanosis & $\begin{array}{c}\text { Sella } \\
\text { Enlargement }\end{array}$ & $\begin{array}{l}\text { Corticoids } \\
\text { 17-OHCS }\end{array}$ & $\begin{array}{l}\text { Corticoid Response } \\
\text { to A.C.T.H. }\end{array}$ & $\begin{array}{l}\text { Plasma } \\
\text { A.C.T.H. }\end{array}$ \\
\hline 1951 & $\cdots$ & ++ & 0 & 0 & + & & \\
\hline January 1952 & $\cdots$ & \multicolumn{6}{|c|}{ Pituitary irradiation-slight temporary improvement } \\
\hline April $1954 \ldots$ & $\cdots$ & +++ & 0 & & $\begin{array}{l}\text { Urine-12 mg./day } \\
\text { Plasma-15 } \mu \mathrm{g} . / 100 \mathrm{ml} \text {. }\end{array}$ & ++ & \\
\hline July $1954 \quad \ldots$ & $\cdots$ & \multicolumn{6}{|c|}{ Subtotal adrenalectomy-no substitution therapy-marked clinical improvement } \\
\hline $\begin{array}{l}\text { May } 1956 \text { ij56 } \\
\text { November } 1956 \\
\text { Summer } 1957\end{array}$ & $\begin{array}{l}\cdots \\
\cdots \\
\cdots\end{array}$ & $\begin{array}{c}\mathbf{0} ? \\
\mathbf{0} ? \\
+\rightarrow+++ \\
\end{array}$ & $\begin{array}{l}+ \\
+ \\
+\end{array}$ & & $\begin{array}{l}\text { Urine-5 mg./day } \\
\text { Plasma }-13 \mu \mathrm{g} . / 100 \mathrm{ml} .\end{array}$ & 0 & \\
\hline January 1958 & - & \multicolumn{6}{|c|}{ Total adrenalectomy-therapy with cortisone and 9- $\alpha$ fluoro-hydrocortisone } \\
\hline $\begin{array}{l}\text { January } 1959 \\
\text { July } 1960 \quad \ldots\end{array}$ & $\begin{array}{l}\cdots \\
\cdots\end{array}$ & $\begin{array}{l}0 \\
0\end{array}$ & $\begin{array}{c}+++ \\
++++\end{array}$ & $\begin{array}{c}++ \\
+++\end{array}$ & & & 144 i.u./100 ml. \\
\hline September 1960 & $\cdots$ & \multicolumn{6}{|c|}{ Implantation of radioactive gold into pituitary } \\
\hline March 1961 & $\cdots$ & 0 & decreased & & & & 5 i.u. $/ 100 \mathrm{ml}$ \\
\hline
\end{tabular}

test. In July 1954 a subtotal adrenalectomy was carried out, leaving only one-tenth of the right adrenal. After this she showed no clinical evidences of adrenal insufficiency and was given no therapy.

During the next three years there was marked improvement in her appearance. She grew three inches. Menstruation occurred regularly. Striae disappeared. In May 1956 , the urinary 17 -hydroxycorticoids were $4 \cdot 6$ mg./day and the 17-ketosteroids $5.5 \mathrm{mg}$./day. At this time slight increase in brownish pigmentation over the knuckles was noted. In November 1956 the plasma 17-hydroxycorticoids had risen to $13 \mu \mathrm{g} . / 100 \mathrm{ml}$. and the administration of intravenous A.C.T.H. caused no increase. Beginning in the summer of 1957 a very definite relapse began with reappearance of the characteristic Cushing's signs, including florid striae and ecchymoses.

After considerable debate, in January 1958, the remnant of the adrenal on the right side was removed. It had increased to the size of a golf ball. Since this time she has been maintained constantly on substitution therapy with $37 \cdot 5-50 \mathrm{mg}$. of cortisone and $0.1 \mathrm{mg}$. of 9-alphafluorohydrocortisone daily. All signs of Cushing's syndrome disappeared. Menstruation occurred regularly. However, brownish pigmentation of the skin of an Addison type increased progressively until she began to be mistaken for a negress. There was also pigmentation of the gingival mucosa. Menstruation stopped after March 1960. There were no headaches or other intracranial symptoms. Radiographs, however, taken in 1959 and 1960 showed progressive enlargement of the sella turcica with a 'double floor' (the sella had been quite small in 1951 when she developed Cushing's symptoms).

It was considered that she had developed an expanding pituitary adenoma which was producing A.C.T.H. and melanocyte-stimulating hormone (M.S.H.). An assay of the plasma A.C.T.H. by Dr. D. Nelson showed the very high level of 144 i.u./100 ml., but we were unable to have a M.S.H. assay performed. It was decided to treat the tumour, which was shown by tomographs to be on the right side of the gland, by implantation into it of a pellet of radioactive gold. On September 8, 1960, a 32-millicurie pellet was inserted by Dr. G. Udvarhelyi through the nasal route under local anaesthesia. No complications ensued. Since then there has been progressive depigmentation. By October 22, the plasma A.C.T.H. decreased to 5 i.u./100 ml. She had one menstrual period in November, indicating that the radiation did not destroy gonadotropic function and that decrease in the size of the tumour may have improved this function of the pituitary. There are no signs of thyrotropic failure.

The occurrence of pituitary tumours after adrenalectomy for Cushing's syndrome raises many questions. Salassa et al. (1959) of the Mayo Clinic reported 12 cases of chromophobe adenoma of the pituitary among 122 patients with Cushing's syndrome, who did not have adrenal tumours. In only three of these cases was there evidence that the tumour was present before adrenalectomy, but adrenalectomy seemed to favour the growth of the tumours and increasing melanosis.

In our case the hyperpigmentation began after the subtotal adrenalectomy in 1954. Presumably excessive compensatory A.C.T.H. secretion also occurred to protect the patient from adrenal deficiency. Was an A.C.T.H. + M.S.H.-producing neoplasm present originally as the primary cause of the Cushing's syndrome, and was this merely caused to enlarge by the adrenalectomy? Although the sella was originally quite small, a very small but actively functioning neoplasm may have been present. If the development and growth of a pituitary neoplasm are merely the results of the effort of the 
pituitary to compensate for adrenal insufficiency by excessive secretion of A.C.T.H., why do pituitary tumours not occur with untreated Addison's disease due to destruction of the adrenal by tuberculosis or following adrenalectomies for other conditions?

Finally, in view of our present knowledge, what is the best treatment of Cushing's syndrome not due to an adrenocortical neoplasm? If there are radiographic or other evidences of a pituitary neoplasm, irradiation or removal of the tumour seems to be indicated. When there are no signs of a pituitary lesion should treatment be directed toward the adrenal or the pituitary? Many workers are again turning their attention to the pituitary, rather than resorting to adrenalectomy. Subtotal adrenalectomy causes only temporary remission in many cases and total adrenalectomy may lead to an expanding pituitary neoplasm with the hyperpigmentation syndrome. External radiation of the pituitary is a harmless procedure, but gives permanent relief in a relatively small percentage of cases. Perhaps better results can be obtained by partial hypophysectomy through implantation of radioactive gold. If the disorder should be due to minute neoplasms which cannot be detected by radiographs it is possible that by wise selection of radioactive dosage they might be destroyed selectively without impairing other pituitary functions. On the other hand, if the disorder is in the homeostatic regulatory centre of the hypothalamus, more radical destruction of the pituitary might be necessary. The problem can be solved only by therapeutic trials. Fortunately, a number of workers, including Russell Fraser of London and others, are employing radioactive implantation of the pituitary as the primary treatment of Cushing's syndrome and their results can be evaluated in a few years.

Editorial note: Part II of this lecture 'The Adrenogenital Syndrome and its Solution', will be published in a subsequent issue of this journal.

\section{REFERENCES}

Albright, F.(1943). Cushing's syndrome; its pathological physiology, its relationship to the adreno-genital syndrome, and its connection with the problem of the reaction of the body to injurious agents ('Alarm reaction' of Selye). Harvey Lect., 1942-1943, 38, 123. ('Alarm reaction' of Selye). Harvey Lect., 1942-1943, 38, 123.
Conn, J. W. (1955). Primary aldosteronism, a new clinical syndrome J. Lab. clin. Med., 45, 3.

Cushing, H. (1932). The basophil adenomas of the pituitary body and their clinical manifestations (pituitary basophilism). Bull. Johns Hopk. Hosp., 50, 137.

Dorfman, R. I. and Shipley, R. A. (1956). Androgens: Biochemistry, Physiology and Clinical Significance. Wiley, New York.

Gaunt, R. (1955). Biological studies with aldosterone (electrocortin). In Ciba Foundation Colloquia on Endocrinology, Vol. 8, cortin). In Ciba Foundation
p. 228. Churchill, London

p. 228. Churchill, London.
Harrop, G. A., Weinstein, A., Soffer, L. J. and Trescher, J. H. (1933) Diagnosis and treatment of Addison's disease. J. Amer. med. Ass., 100, 1850.

Hartman, F. A., Aaron, A. H. and Culp, J. E. (1930). The use of cortin in Addison's disease. Endocrinology, 14, 438.

Haymaker, W. and Anderson, E. (1938). The syndrome arising from hyperfunction of the adrenal cortex; the adrenogenital and Cushing's syndrome; a review. Int. Clin., n.s. 4, 244.

Ingle, D. J. and Baker, B. L. (1953). Physiological and Therapeutic Effects of Corticotropin (ACTH) and Cortisone. Pubn. no. 179, American Lecture Series, monograph in American Lectures in American Lecture Series, monograph in American Lectures in
Metabolism, ed. by P. György, L. Leiter, and S. O. Waife, Thomas, Springfield, Illinois.

Liddle, G. W. (1960). Tests of pituitary-adrenal suppressibility in the diagnosis of Cushing's syndrome. J. clin. Endocr., 20, 1539.

Loeb, R. F., Atchley, D. W., Benedict, E. M. and Leland, J. (1933). Electrolyte balance studies in adrenalectomized dogs with particular reference to the excretion of sodium. J. exp. Med., 57,

ong, C. N. H., Katzin, B. and Fry, E. G. (1940). The adrena cortex and carbohydrate metabolism. Endocrinology, 26, 309.

Nelson, D. H., Meakin, J. W. and Thorn, G. W. (1960). ACTHproducing pituitary tumors following adrenalectomy for Cushing's syndrome. Ann. int. Med., 52, 560.

Nugent, C. A., Eik-Nes, K., Kent, H. S., Samuels, L. T. and Tyler, F. H. (1960). A possible explanation for Cushing's syndrome associated with adrenal hyperplasia. J. clin. Endocr., 20, 1259.

Pfiffner, J. J. and Swingle, W. W. (1929). The preparation of an active extract of the suprarenal cortex. Anat. Rec., 44, 225.

Salassa, R. M., Kearns, T. P., Kernohan, J. W., Sprague, R. G. and MacCarty, C. S. (1959). Pituitary tumors in patients with Cushing's syndrome. J. clin. Endocr., 19, 1523. 